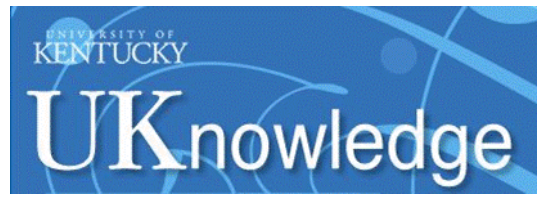

University of Kentucky UKnowledge

\title{
$1-2017$
}

\section{Aluminum and Phthalates in Calcium Gluconate: Contribution from Glass and Plastic Packaging}

Robert A. Yokel

University of Kentucky, ryokel@email.uky.edu

Jason M. Unrine

University of Kentucky, jason.unrine@uky.edu

Right click to open a feedback form in a new tab to let us know how this document benefits you.

Follow this and additional works at: https://uknowledge.uky.edu/ps_facpub

Part of the Pharmacy and Pharmaceutical Sciences Commons, and the Toxicology Commons 


\section{Aluminum and Phthalates in Calcium Gluconate: Contribution from Glass and Plastic Packaging}

Digital Object Identifier (DOI)

https://doi.org/10.1097/MPG.0000000000001243

\section{Notes/Citation Information}

Published in Journal of Pediatric Gastroenterology \& Nutrition, v. 64, no. 1, p. 109-114.

Copyright @ 2017 European Society for Pediatric Gastroenterology, Hepatology, and Nutrition and North American Society for Pediatric Gastroenterology.

The document available for download is the authors' post-peer-review final draft of the article. It is made available under the terms of the Creative Commons Attribution-NonCommercial (CC BY-NC) license. 
Aluminum and phthalates in calcium gluconate; contribution from glass and plastic packaging

Robert A. Yokel, $\mathrm{PhD}{ }^{1,2^{*}}$, Jason M. Unrine, $\mathrm{PhD}^{2,3}$

${ }^{1}$ Pharmaceutical Sciences, ${ }^{2}$ Graduate Center for Toxicology, ${ }^{3}$ Plant and Soil Sciences, University of Kentucky, Lexington, KY

${ }^{*}$ Corresponding author:

Robert A. Yokel, Ph.D.

Department of Pharmaceutical Sciences

335 Biopharmaceutical Complex (College of Pharmacy) Building

College of Pharmacy

University of Kentucky Academic Medical Center

Lexington, KY, 40536-0596

phone: $859-257-4855$

fax: 859-257-7564

e-mail: ryokel@uky.edu

Word count of manuscript body: 2230

Number of figures: 2

Number of Tables: 2

Conflict of interest: Robert Yokel is a founder and President of ALKYMOS, Inc. ALKYMOS was developing a device to remove aluminum from calcium gluconate solution. Given the 
release of Calcium Gluconate Injection USP in plastic packaging in the US, as cited in this report, which has a concentration of aluminum in the range that was achievable with the ALKYMOS device filtered calcium gluconate from glass-packaged product, ALKYMOS has suspended development of its device. Robert Yokel has no further conflict of interest related to this report. Jason Unrine has no conflict of interest related to this report. 


\section{Abstract:}

Introduction: Aluminum contamination of parenteral nutrition solutions has been documented for three decades. It can result in elevated blood, bone, and whole body aluminum levels associated with neurotoxicity, reduced bone mass and mineral content, and perhaps hepatotoxicity. The primary aluminum source among parenteral nutrition components is glass-packaged calcium gluconate, in which aluminum concentration the past three decades has averaged $\sim 4000 \mu \mathrm{g} / \mathrm{L}$, compared to $<200 \mu \mathrm{g} / \mathrm{L}$ in plastic container-packaged calcium gluconate. A concern about plastic packaging is leaching of plasticizers, including phthalates, which have the potential to cause endocrine (male reproductive system) disruption and neurotoxicity. Methods: Aluminum was quantified in samples collected periodically over more than two years from three calcium gluconate sources used to prepare parenteral nutrition solutions; two packaged in glass (from France and the US) and one in plastic (from Germany); in a recently released plasticpackaged solution (from the US); and in the two glass containers. Phthalate concentration was determined in selected samples of each product and leachate of the plastic containers. Results: The initial aluminum concentration was $\sim 5000 \mu \mathrm{g} / \mathrm{L}$ in the two glass-packaged products and $\sim 20 \mu \mathrm{g} / \mathrm{L}$ in the plastic-packaged product, and increased $\sim 30,50$ and $100 \%$ over 2 years, respectively. The aluminum concentration in a recently released Calcium Gluconate Injection USP was $\sim 320 \mu \mathrm{g} / \mathrm{L}$. Phthalates were not detected in any calcium gluconate solutions or leachates. Conclusion: Plastic packaging greatly reduces the contribution of aluminum to parenteral nutrition solutions from calcium gluconate compared to the glass-packaged product. 
What is known:

- Aluminum is a contaminant of parenteral nutrition solutions.

- Aluminum can cause neurotoxicity, reduced bone mass and mineral content, and perhaps hepatotoxicity.

- Glass-packaged calcium gluconate is the primary aluminum source of parenteral nutrition solutions.

What is new:

- As received glass-packaged calcium gluconate provides aluminum in excess of the FDA's recognized level that results in aluminum accumulation associated with central nervous system and bone toxicity.

- Aluminum in calcium gluconate increases over two years of storage.

- Calcium gluconate packaged in the tested plastic containers does not provide aluminum in excess of the FDA level or measurable phthalates (plasticizers with potential to cause male reproductive system disruption and neurotoxicity). 


\section{Introduction:}

Aluminum contamination of parenteral nutrition solutions has been a documented problem for three decades (1-4), which can result in elevated blood aluminum (5), increased body burden $(5,6)$, increased bone aluminum (7), neurotoxicity (8), reduced bone mass and mineral content $(6,9)$, and perhaps hepatotoxicity $(10,11)$. This led to a US FDA labeling requirement addressing this issue, which concludes that "patients with impaired kidney function, including premature neonates, who receive parenteral levels of aluminum at greater than 4 to 5 [micro]g/kg/day accumulate aluminum at levels associated with central nervous system and bone toxicity" (12). The primary source of aluminum in parenteral nutrition solutions is calcium gluconate, reported to contribute up to $88 \%$ vs. 4\% from phosphates (13), $88.7 \%$ (14), $78 \%$ to home parenteral nutrition solutions (15), 81 vs. $9 \%$ from sodium phosphate (16), 50\% (17), $80 \%$ to $98 \%$ (18), 80 $\pm 22 \%$ (19), the main source of aluminum (20), and highest amounts were provided by dextrose and calcium gluconate (21). The raw material was identified as one, but not the sole source (22). The aluminum primarily comes from glass packaging (23-26). Aluminum is added to the glass of containers of parenteral solutions to improve resistance to chemical attack and thermal shock (27).

Table 1 shows the reported concentrations of aluminum in calcium gluconate used to prepare parenteral nutrition solutions. Most of these values indicate that the aluminum concentration in this product, when packaged in glass, has averaged $\sim 4000 \mu \mathrm{g} / \mathrm{L}$, and has not decreased over the past three decades. Excluding three high values there has 
been a non-significant increase in the aluminum concentration in calcium gluconate packaged in glass over the past three decades (Figure 1).

The average daily administration of aluminum to premature and term infants has been found to be 15 to $25 \mu \mathrm{g} / \mathrm{kg}(5,39,43,44)$, or three to five times the upper boundary of the US FDA guideline, and even higher in Argentina (21). In the United States, until mid2015, Calcium Gluconate Injection USP had only been available in glass packaging. Pharmacists had few opportunities to minimize aluminum administration in parenteral nutrition solutions, limited to using the most recently obtained product, based on the assumption that the aluminum concentration increases over storage time in the glass container $(4,45)$, as shown by one study cited in Table $1(40)$.

A few reports have shown much less aluminum in calcium gluconate packaged in plastic containers (Table 1) $(37,40)$. There have been encouragements to abandon glass packaged calcium gluconate in favor of plastic packaging $(20,40)$. A concern about plastic packaging is the possibility that the product contains leached plasticizers, particularly phthalates such as DEHP (bis(2-ethylhexyl) phthalate, aka: di-2-ethylhexyl phthalate, diethylhexyl phthalate). Phthalates have the potential to cause endocrine (male reproductive system) disruption and neurotoxicity. Infants are the most susceptible population $(46,47)$. Plasticizers might present a hazard not inherent to glass containers, although the rubber stopper of glass vials could be a source. 
The present study was conducted to quantify the aluminum concentration over the shelf life of representative calcium gluconate solutions used to prepare parenteral nutrition solutions, and to determine the initial aluminum concentration and the rate and extent of aluminum concentration increase over storage time. The concentration of phthalates, including DEHP, was determined to ascertain if calcium gluconate provided a risk from exposure to these plasticizers. 


\section{Methods:}

Multiple containers of calcium gluconate solutions used in the preparation of parenteral nutrition solutions were obtained from three sources in July, 2013; APP Pharmaceuticals, LLC, US, packaged in glass; C.D.M. Lavoisier, France, packaged in glass; and B. Braun, Germany, packaged in plastic. A single vial packaged in glass was obtained from Fresenius Kabi, LLC, US, in May, 2015. Approximately half of the $10 \mathrm{~mL}$ calcium gluconate contents of individual containers from APP Pharmaceuticals and B. Braun was clean poured into duplicate seven $\mathrm{mL}$ perfluoroalkoxy alkanes (PFA) vials at 1.5 month intervals from July 19, 2013 through August 25, 2015. The interval between sample transfers of the Lavoisier product was every 3 months after the first three samples. The Fresenius Kabi product was similarly transferred on September 8, 2015. The duplicate calcium gluconate samples were analyzed by inductively coupled plasma - mass spectrometry (ICP-MS) to quantify their aluminum concentration. The aluminum content of one of the glass vials from APP Pharmaceuticals and one of the glass ampoules from Lavoisier was determined by ICP-MS. Selected calcium gluconate samples were analyzed by gas chromatography - mass spectrometry (GC-MS) to quantify 8 phthalates. Leachable phthalates from one of the B. Braun plastic containers and the Fresenius Kabi plastic container were determined by GC-MS. Details are reported in the Supplemental Information.

Data analysis:

Outliers of the ICP-MS analysis of aluminum in the calcium gluconate solutions were identified using the Grubb outlier test (http://graphpad.com/quickcalcs/Grubbs1.cfm) 
subjecting all results for samples from the same source to the test. One sample of the Lavoisier, four samples of the B. Braun, and two water blanks were identified as outliers and were removed from further data analysis. The average aluminum concentration of the two-hundred fold diluted water blanks $(0.45 \mu \mathrm{g} / \mathrm{L})($ S.D. $=0.14 \mu \mathrm{g} / \mathrm{L})$ was subtracted from each two-hundred fold diluted calcium gluconate value. The average aluminum concentration of the duplicate (collected same day) samples was plotted against time, starting with time $=0$ when the first samples were transferred from their original containers to the PFA vials (July 19, 2013). Linear regression of aluminum concentration versus time was determined using GraphPad Prism 6 (GraphPad Software, Inc., La Jolla, CA). The aluminum content of the glass containers was compared by a t-test. 


\section{Results:}

Aluminum analysis:

The instrument detection limit was $0.068 \mu \mathrm{g} / \mathrm{L}$ aluminum. The method detection limit (accounting for required dilution) was $13.6 \mu \mathrm{g} / \mathrm{L}$ aluminum. Aluminum concentration in the two analytical duplicates was 111 and $116 \%$ of the original sample. Spike recovery was 104 and $106 \%$ for two samples. The aluminum concentration in all samples was greater than the instrument detection limit; the lowest was $0.29 \mu \mathrm{g} / \mathrm{L}$ in a water blank. Aluminum concentration in the calcium gluconate samples is shown in Figure 2. The slope of aluminum concentration versus time for the APP product was significantly different from zero $(F(1,15) 58.35, P<0.0001)$, for the Lavoisier product was not significantly different from zero $(F(1,8) 3.75, P=0.089)$, and for the $B$. Braun product was $(F(1,14) 15.02, P<0.0017)$. The aluminum concentration in the duplicate samples from the sole Fresenius Kabi sample collected September 8, 2015 averaged $318 \mu \mathrm{g} / \mathrm{L}$. The aluminum concentrations in the glass vial from APP Pharmaceuticals and the glass ampoule from Lavoisier were not statistically different.

\section{Phthalate analysis:}

The blank samples had $<0.02 \mathrm{mg} / \mathrm{L}$ of the phthalates. DEHP recovery from spiked water and Calcium Gluconate Injection USP samples was 86 and $91 \%$, respectively. Recovery of the other six phthalates ranged from 76 to $100 \%$ (mean $=89 \%$ ). Recovery of the surrogates ranged from 69 to $98 \%$ (mean $=89 \%$ ). Recovery of p-terphenyl-d14, that eluted closest to most of the phthalates (20.92 minutes), was $89 \%$ from water, $93 \%$ from the Calcium Gluconate Injection USP blank, and ranged from 74 to $102 \%$ (mean = 
$93 \%)$ from the eight tested samples. Recovery of the other two surrogates ranged from 69 to $98 \%$ from the blanks and 33 to $98 \%$ (mean $=80 \%$ ) from the eight tested samples. The concentrations of the seven phthalates in the eight tested one $\mathrm{mL}$ dichloromethane extracts of four to five $\mathrm{mL}$ calcium gluconate were less than the lowest standard $(0.1$ $\mathrm{mg} / \mathrm{L}$ ), therefore there was $<0.025 \mathrm{mg} / \mathrm{L}$ phthalates in all samples. No phthalates were detected in dichloromethane extracts of either the B. Braun or Fresenius Kabi container. 


\section{Discussion:}

The initial aluminum concentration in calcium gluconate in the APP vials and Lavoisier ampoules was $\sim 4800 \mu \mathrm{g} / \mathrm{L}$ (Figure 2), slightly higher than the average reported aluminum concentration in calcium gluconate packaged in glass over the past three decades (Figure 1). A typical initial parenteral nutrition calcium dose for neonates is 2 $\mathrm{mEq} / \mathrm{kg}$ (48), which would be delivered in $4.3 \mathrm{~mL}$ of $10 \%$ calcium gluconate $(0.465$ $\mathrm{mEq} / \mathrm{mL} \mathrm{Ca}$ ). $4.3 \mathrm{~mL}$ of $4800 \mu \mathrm{g} / \mathrm{L}$ aluminum would deliver $\sim 20 \mu \mathrm{g} / \mathrm{kg} /$ day aluminum, exceeding the FDA guideline of four to five $\mu \mathrm{g} / \mathrm{kg} / \mathrm{day}$, and consistent with the average daily administration of aluminum to premature and term infants of 15 to $25 \mu \mathrm{g} / \mathrm{kg}$, cited in the Introduction. The FDA's labeling requirement that requires a statement of the maximum level of aluminum present at expiry on the container label of small volume parenteral drug products does not resolve the problem of aluminum contamination of parenteral nutrition solutions. It permits aluminum concentrations in small volume parenterals that result in aluminum concentrations in parenteral nutrition solutions in excess of aluminum accumulation associated with central nervous system and bone toxicity. The use of calcium gluconate solutions packaged in glass shortly after their receipt by the end user would not successfully address the aluminum contamination problem.

Aluminum concentration increased over time, as previously reported (40). There is a significant slope (increase of aluminum concentration over time) for the APP product packaged in glass, but not the Lavoisier product also packaged in glass. The increase of aluminum in the Lavoisier product over time ( 30\%) was less than in the APP 
product ( 50\%). The Lavoisier product contained 7\% calcium gluconate and $3 \%$ calcium glucoheptonate (aka gluceptate) compared to $10 \%$ calcium gluconate in the APP product. The binding affinity of gluconate for aluminum (49) is large enough to attribute the increase of aluminum over time in calcium gluconate to the leaching of aluminum from the glass containers. No aluminum glucoheptonate stability constant was found in the literature. As the structures of gluconate and glucoheptonate are very similar there is no reason to expect a significant difference in their aluminum binding affinities. The presence of calcium glucoheptonate in the Lavoisier product is unlikely to account for the difference in rate of aluminum increase in these products. The amount of aluminum in the glass vial from APP was not different from the glass ampoule from Lavoisier (Supplemental Information). Package inserts do not inform about the type of glass. The USP monograph for Calcium Gluconate Injection states that the solution should be preserved in single-dose containers, preferably of Type I glass. Type I glass is used to manufacture ampoules. It is not clear if there are differences in the glass composition of the APP and Lavoisier product containers that influenced the rate of aluminum increase over time in calcium gluconate stored in those containers. Irrespective of the glass source, using a calcium gluconate solution from a glass package that has been on the shelf for some time exacerbates the problem of aluminum contamination.

Switching calcium gluconate from glass to plastic packaging does not remove all parenteral nutrition component sources of aluminum. Plastic packaged calcium gluconate contains measurable aluminum (Table 1 and results of this study). Other 
components of parenteral nutrition solutions and intravenous therapy of neonates are also contaminated with aluminum. Three of concern are phosphates, heparin, and albumin. Table 2 contains the aluminum concentrations in phosphates, heparin, and albumin reported in the publications cited in Table 1. There are reports of aluminum concentrations in 18 phosphate solutions in which the phosphate concentration is sufficiently reported to calculate aluminum (in $\mu \mathrm{g}$ ) in one $\mathrm{mmol}$ of phosphate $(2,17,22$, $25,28,30,33,34,41)$, the phosphate dose to initiate parenteral nutrition per kg patient body weight (48). The median aluminum concentration of the 18 solutions is $1400 \mu \mathrm{g} / \mathrm{L}$, which would deliver $1.4 \mu \mathrm{g}$ aluminum per mmol phosphate. Compared to the $\sim 20 \mu \mathrm{g}$ of aluminum from calcium gluconate that would be in parenteral nutrition solution for a $1 \mathrm{~kg}$ neonate (above), calcium gluconate is a greater contributor. The aluminum contribution from heparin to parenteral nutrition solutions is negligible, given its suggested concentration in parenteral nutrition solutions is $1 \mathrm{U} / \mathrm{mL}(48)$. As albumin is not a routine component of parenteral nutrition solutions its contribution compared to calcium gluconate is not made. However, large, repeated albumin doses might present a significant amount of aluminum.

The problem of aluminum contamination of calcium gluconate can be largely avoided by the use of plastic packaging, as has been suggested $(20,40)$. The present results support that suggestion.

A concern for products packaged in plastic is the potential release of plasticizers from the container into the product. The phthalates are of particular concern, especially for infants. The maximum allowable dose for DEHP by intravenous injection to neonatal 
infant boys (birth to 28 days of age) is $210 \mu \mathrm{g} /$ day (50). Based on the typical initial parenteral calcium dose for a neonate of average weight $(3.4 \mathrm{~kg})$, which would be delivered in $~ 14.6 \mathrm{~mL}$ of $10 \%$ calcium gluconate, the maximum allowable level of DEHP in calcium gluconate is $\sim 15 \mu \mathrm{g} / \mathrm{mL}$. None of the samples had $>0.2 \%$ of this level.

The results of the present study, and prior reports of aluminum contamination of calcium gluconate packaged in glass and plastic, and the lack of phthalate plasticizers in calcium gluconate packaged in plastic, support the suggestions that glass-packaged calcium gluconate should be avoided as a component of parenteral nutrition solutions delivered to patients with impaired kidney function. The recent introduction in the US of plastic container packaged calcium gluconate should enable the preparation of parenteral nutrition solutions with considerably reduced aluminum content, to the benefit of patients with impaired kidney function, including premature neonates. 
Acknowledgments and Permissions: The authors thank Dr. Robert Kuhn, Kentucky Children's Hospital, for obtaining the APP and Fresenius products; Dr. Kathleen Gura, Boston Children's Hospital, for obtaining the Lavoisier and B. Braun products; John May, Environmental Research Training Laboratories, University of Kentucky, for conducting the phthalate assays; and Shristi Shrestha, for assistance with sample preparation and aluminum analysis. 


\section{References:}

1 Klein GL, Leichtner AM, Heyman MB, et al. Aluminum in large and small volume parenterals used in total parenteral nutrition: response to the Food and Drug Administration notice of proposed rule by the North American Society for Pediatric Gastroenterology and Nutrition. J Pediatr Gastroenterol Nutr 1998;27(4):457-60.

2 Sedman AB, Klein GL, Merritt RJ, et al. Evidence of aluminum loading in infants receiving intravenous therapy. N Eng J Med 1985;312(21):1337-43.

3 Von Stockhausen HB, Schrod L, Braetter P, et al. Aluminum loading in premature infants during intensive care as related to clinical aspects. J Trace Elem Electrolyte Health Disease 1990;4(4):209-13.

$4 \quad$ Hernandez-Sanchez A, Tejada-Gonzalez P, Arteta-Jimenez M Aluminium in parenteral nutrition: a systematic review. Eur J Clin Nutr 2013;67(3):230-8.

5 Courtney-Martin G, Kosar C, Campbell A, et al. Plasma aluminum concentrations in pediatric patients receiving long-term parenteral nutrition. JPEN J Parenter Enteral Nutr 2015;39(5):578-85.

6 Appleman SS, Kalkwarf HJ, Dwivedi A, et al. Bone deficits in parenteral nutritiondependent infants and children with intestinal failure are attenuated when accounting for slower growth. J Pediatr Gastroenterol Nutr 2013;57(1):124-30.

7 Kruger PC, Parsons PJ, Galusha AL, et al. Excessive aluminum accumulation in the bones of patients on long-term parenteral nutrition: postmortem analysis by electrothermal atomic absorption spectrometry. JPEN J Parenter Enteral Nutr 2013;38(6):728-35. 
8 Bishop NJ, Morley R, Day JP, et al. Aluminum neurotoxicity in preterm infants receiving intravenous-feeding solutions N Eng J Med 1997;336(22):1557-61.

9 Fewtrell MS, Bishop NJ, Edmonds CJ, et al. Aluminum exposure from parenteral nutrition in preterm infants: bone health at 15-year follow-up. Pediatrics 2009;124(5):1372-79.

10 Demircan M, Ergun O, Coker C, et al. Aluminum in total parenteral nutrition solutions produces portal inflammation in rats. J Pediatr Gastroenterol Nutr 1998;26(3):274-78.

11 Arnold CJ, Miller GG, Zello GA Parenteral nutrition-associated cholestasis in neonates: the role of aluminum. Nutr Rev 2003;61(9):306-10.

12 US FDA. Aluminum in large and small volume parenterals used in total parenteral nutrition. 201.323. Vol Code of Federal Regulations, Title 21, Volume 4 -- Food and drugs - Chapter I -- Food and Drug Administration DHHS, Subchapter C- Drugs: General, Part 201 -- Labelling, Subpart G - Specific labeling requirements for specific drug products, Sec. 201.323; 2012. http://www.accessdata.fda.gov/scripts/cdrh/cfdocs/cfcfr/cfrsearch.cfm?fr=201.323

13 Koo WWK, Kaplan LA, Horn J, et al. Aluminum in parenteral nutrition solution-sources and possible alternatives. JPEN J Parenter Enteral Nutr 1986;10(6):59195.

14 Rabinow BE, Ericson S, Shelborne T Aluminum in parenteral products: analysis, reduction, and implications for pediatric TPN. J Parenteral Sci Technol 1989;43(3):132-38. 
15 Douet C, Accominotti M, Barbieux A [Calcium salts role in the aluminum contamination of parenteral nutrition solutions]. J Pharm Clinique 1996;15(1):2126.

16 Mouser JF, Wu AH, Herson VC Aluminum contamination of neonatal parenteral nutrient solutions and additives. Am J Health Syst Pharm 1998;55(10):1071-72.

17 Advenier E, Landry C, Colomb V, et al. Aluminum contamination of parenteral nutrition and aluminum loading in children on long-term parenteral nutrition. $\mathrm{J}$ Pediatr Gastroenterol Nutr 2003;36(4):448-53.

18 de Oliveira SR, Bohrer D, Garcia SC, et al. Aluminum content in intravenous solutions for administration to neonates: role of product preparation and administration methods. JPEN J Parenter Enteral Nutr 2010;34(3):322-8.

19 Brown RO, Morgan LM, Bhattacharya SK, et al. Potential aluminum exposure from parenteral nutrition in patients with acute kidney injury. Ann Pharmacother 2008;42(10):1410-15.

20 Lima-Rogel V, Romano-Moreno S, de Jesus Lopez-Lopez E, et al. Aluminum contamination in parenteral nutrition admixtures for low-birth-weight preterm infants in Mexico. JPEN J Parenter Enteral Nutr 2014; first published September $16,2014($

21 Menéndez AM, Farías SS, Servant R, et al. [Aluminum content in individual components, used to prepare adult total parenteral nutrition mixtures in Argentine, and in comparison with international regulation]. Nutr Hosp 2014;29(6):1380-7. 
22 Bohrer D, do Nascimento P, Binotto R, et al. Contribution of the raw material to the aluminum contamination in parenterals. JPEN J Parenter Enteral Nutr 2002;26(6):382-88.

23 Bohrer D, do Nascimento PC, Binotto R, et al. Influence of the glass packing on the contamination of pharmaceutical products by aluminium. Part I: salts, glucose, heparin and albumin. J Trace Elem Med Biol 2001;15(2-3):95-101.

24 Bohrer D, Cicero do Nascimento P, Binotto R, et al. Influence of the glass packing on the contamination of pharmaceutical products by aluminium. Part II: Amino acids for parenteral nutrition. J Trace Elem Med Biol 2001;15(2-3):103-08.

25 Bohrer D, do Nascimento PC, Binotto R, et al. Influence of the glass packing on the contamination of pharmaceutical products by aluminium. Part III: Interaction container-chemicals during the heating for sterilisation. J Trace Elem Med Biol 2003;17(2):107-15.

26 Biavati A, Amadei P, Ferrarini A, et al. Significance of aluminium release from type I borosilicate glass containers. Pharmazeutische Industrie 2010;72(12):2144-47.

27 Bohrer D, do Nascimento PC, Becker E, et al. Critical evaluation of the standard hydrolytic resistance test for glasses used for containers for blood and parenteral formulations. PDA J Pharm Sci Technol 2004;58(2):96-105.

28 Børresen HC Aluiminiumforgiftning ved intravenøs ernæring av barn. Tidsskr Nor Lægeforen 1986;4(106):295-96.

29 McGraw M, Bishop N, Jameson R, et al. Aluminium content of milk formulae and intravenous fluids used in infants. Lancet 1986;1(8473):157. 
30 Fewtrell MS, Edmonds CJ, Isaacs E, et al. Aluminium exposure from parenteral nutrition in preterm infants and later health outcomes during childhood and adolescence. Proc Nutr Soc 2011;70(3):299-304.

31 Berner YN, Shuler TR, Nielsen FH, et al. Selected ultratrace elements in total parenteral nutrition solutions. Am J Clin Nutr 1989;50(5):1079-83.

32 Larchet $\mathrm{M}$, Chaumont $\mathrm{P}$, Galliot $\mathrm{M}$, et al. Aluminium loading in children receiving long-term parenteral nutrition. Clin nutr (Edinburgh, Scotland) 1990;9(2):79-83.

33 Montero CG, Morales E, Vilchez T, et al. Aluminum content of total parenteral nutrition solutions. J Clin Nutr Gastroenterol 1991;6(3):131-36.

34 Hayes P, Martin TP, Pybus J Aluminium content of intravenous solutions, additives and equipment used to prepare nutrition mixtures. Aust J Hospital Pharm 1992;22(353-59.

35 Recknagel S, Brätter P, Chrissafidou A, et al. Parenteral aluminum loading in critical care medicine. Part I: Aluminum content of infusion solutions and solutions for parenteral nutrition. Infusionsther Transfusionsmed 1994;21(4):26673.

36 Popińska K, Kierkuś J, Lyszkowska M, et al. Aluminum contamination of parenteral nutrition additives, amino acid solutions, and lipid emulsions. Nutrition 1999;15(9):683-86.

37 Frey OR, Maier L Polyethylene vials of calcium gluconate reduce aluminum contamination of TPN. Ann Pharmacother 2000;34(6):811-12. 
38 Alvarez L, Rebollido M, Fernandez-Lorenzo JR, et al. Electrothermal atomic absorption spectrometry determination of aluminium in parenteral nutrition and its components. J Trace Elem Med Biol 2007;21 Suppl 1(29-30.

39 Poole RL, Schiff L, Hintz SR, et al. Aluminum content of parenteral nutrition in neonates: measured versus calculated levels. J Pediatr Gastroenterol Nutr 2010;50(2):208-11.

40 Beaney A, Smeaton M. Aluminium levels in parenteral nutrition - time to change to plastic ampoules of calcium gluconate? 15th Congress of the European Association of Hospital Pharmacists. Nice, France; 2010.

41 Poole RL, Pieroni KP, Gaskari S, et al. Aluminum in pediatric parenteral nutrition products: measured versus labeled content. J Pediatr Pharmacol Ther 2011;16(2):92-97.

42 Yokel RA, Harris WR, Spilling CD, et al. A filtration system that greatly reduces aluminum in calcium gluconate injection, USP used to prepare parenteral nutrition solutions. J Pediatr Pharmacol Ther 2014;19(3):189-95.

43 Bohrer D, Oliveira SM, Garcia SC, et al. Aluminum loading in preterm neonates revisited. J Pediatr Gastroenterol Nutr 2010;51(2):237-41.

44 Aitichou $\mathrm{M}$, Laleye $\mathrm{D}$, Pirot $\mathrm{F}$, et al. Aluminium content in parenteral nutrition compounds and in parenteral nutrition admixtures: between practice and recommendations. 39th ESCP European symposium on clinical pharmacy \& 13th SFPC congress: clinical pharmacy at the front line of innovations. Lyon, France: Int J Clin Pharm; 2010:391-92. 
45 Wier HA, Kuhn RJ Aluminum toxicity in neonatal parenteral nutrition: What can we do? Ann Pharmacother 2012;46(137-40.

46 Miodovnik A, Edwards A, Bellinger DC, et al. Developmental neurotoxicity of ortho-phthalate diesters: Review of human and experimental evidence. NeuroToxicology 2014;41(112-22.

47 Kay VR, Bloom MS, Foster WG Reproductive and developmental effects of phthalate diesters in males. Crit Rev Toxicol 2014;44(6):467-98.

48 UCSF Children's Hospital. (2004-2006) Intensive Care Nursery House Staff Manual - Neonatal Parenteral Nutrition. https://www.ucsfbenioffchildrens.org/pdf/manuals/47 TPN.pdf..

49 Motekaitis RJ, Martell AE Complexes of aluminum(III) with hydroxy carboxylic acids. Inorg Chem 1984;23(18-23.

50 California Office of Environmental Health Hazard Assessment (OEHHA) Reproductive and Cancer Hazard Assessment Section. (2006) Five proposition 65 maximum allowable dose level (MADL) for reproductive toxicity for di(2ethylhexyl)phthalate (DEHP) by intravenous injection.

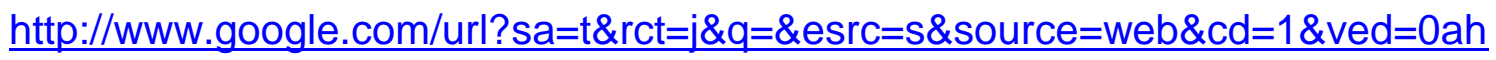
UKEwjK3p3S5pPKAhVJVh4KHSRyDN0QFggcMAA\&url=http\%3A\%2F\%2Foehh a.ca.gov\%2Fprop65\%2Flaw\%2Fpdf zip\%2FFeb2006DEHPclear.pdf\&usg=AFQj CNGtvD5DhGMZ H480S1JsaMudTR73w\&bvm=bv.110151844,d.dmo. 


\section{Figure legends}

Figure 1. Aluminum concentration of calcium gluconate packaged in glass. The values are from Table 1 with the exclusion of 10,695 reported by (35) and values reported by (18). Line is best fit of the data points.

Figure 2. Aluminum concentration in $10 \%$ calcium gluconate from single lots collected over time. Values are the mean of the duplicate samples collected on and after the date of the first sample (time $=0$ ). Note the different $Y$ axis scale for the $B$. Braun product. Line is best fit of the results. 


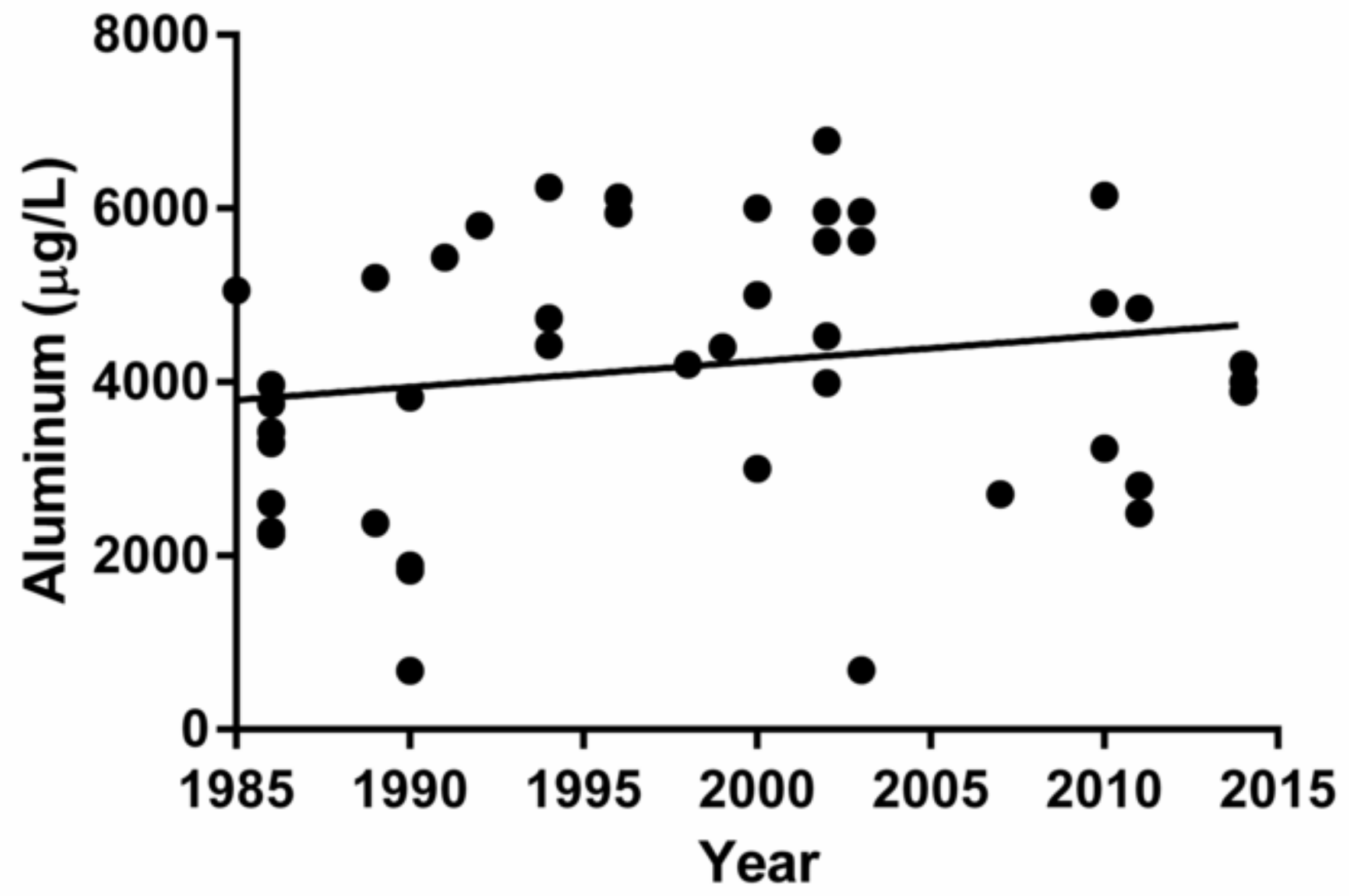




\section{$10 \%$ Calcium gluconate packaged in glass vials from APP}

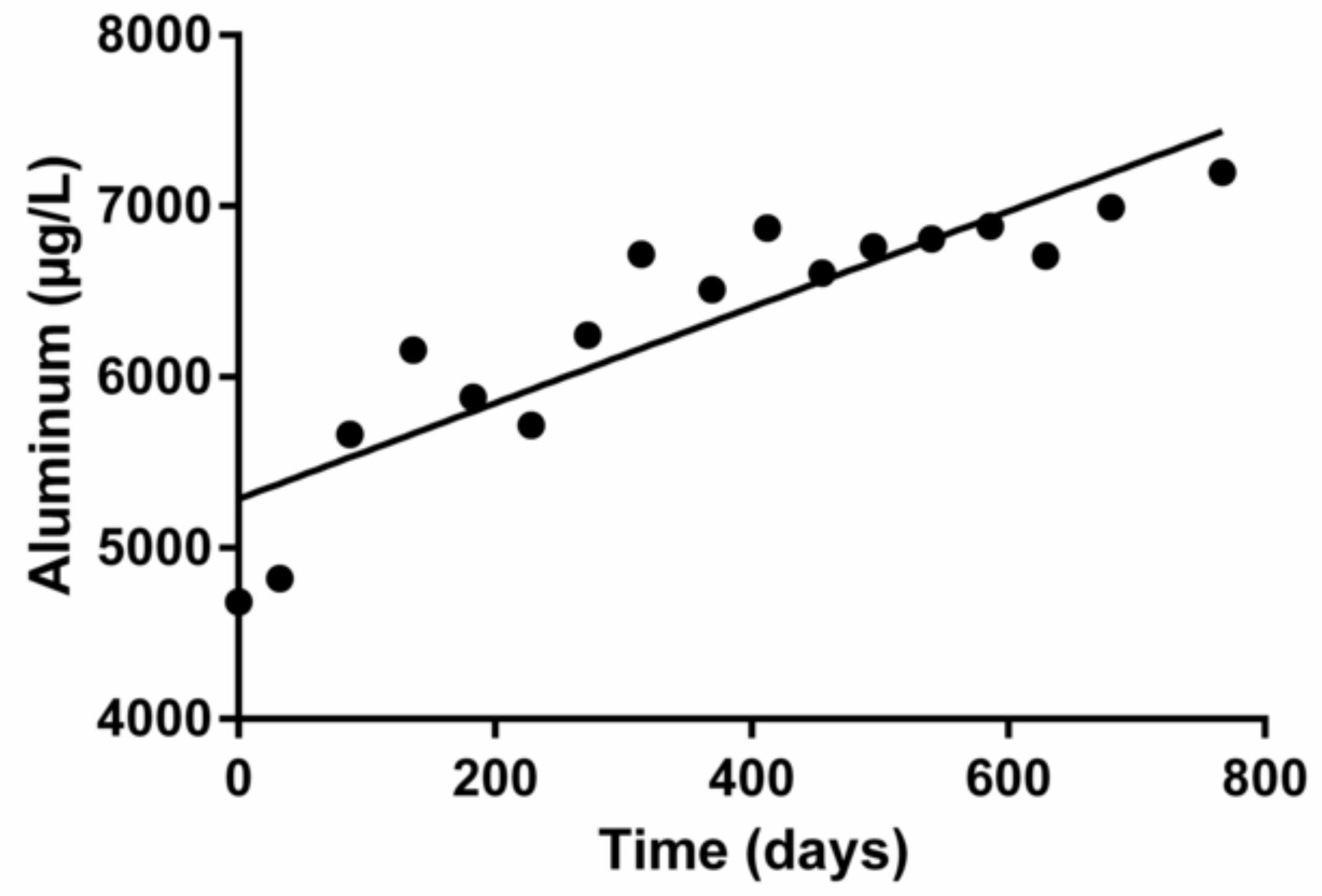




\section{$10 \%$ Calcium gluconate packaged in glass ampoules from Lavoisier}

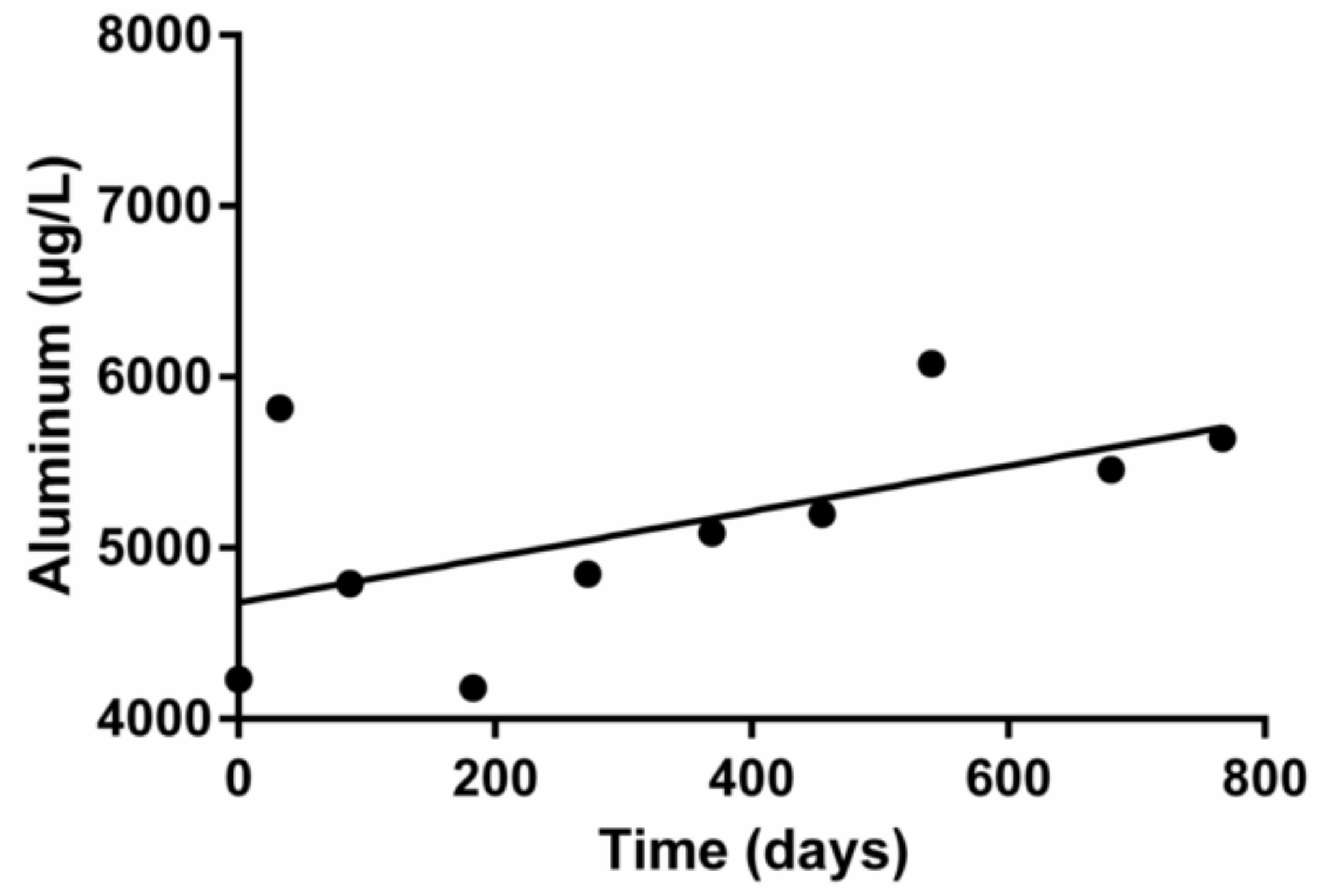




\section{$10 \%$ Calcium gluconate packaged in plastic ampoules from B. Braun}

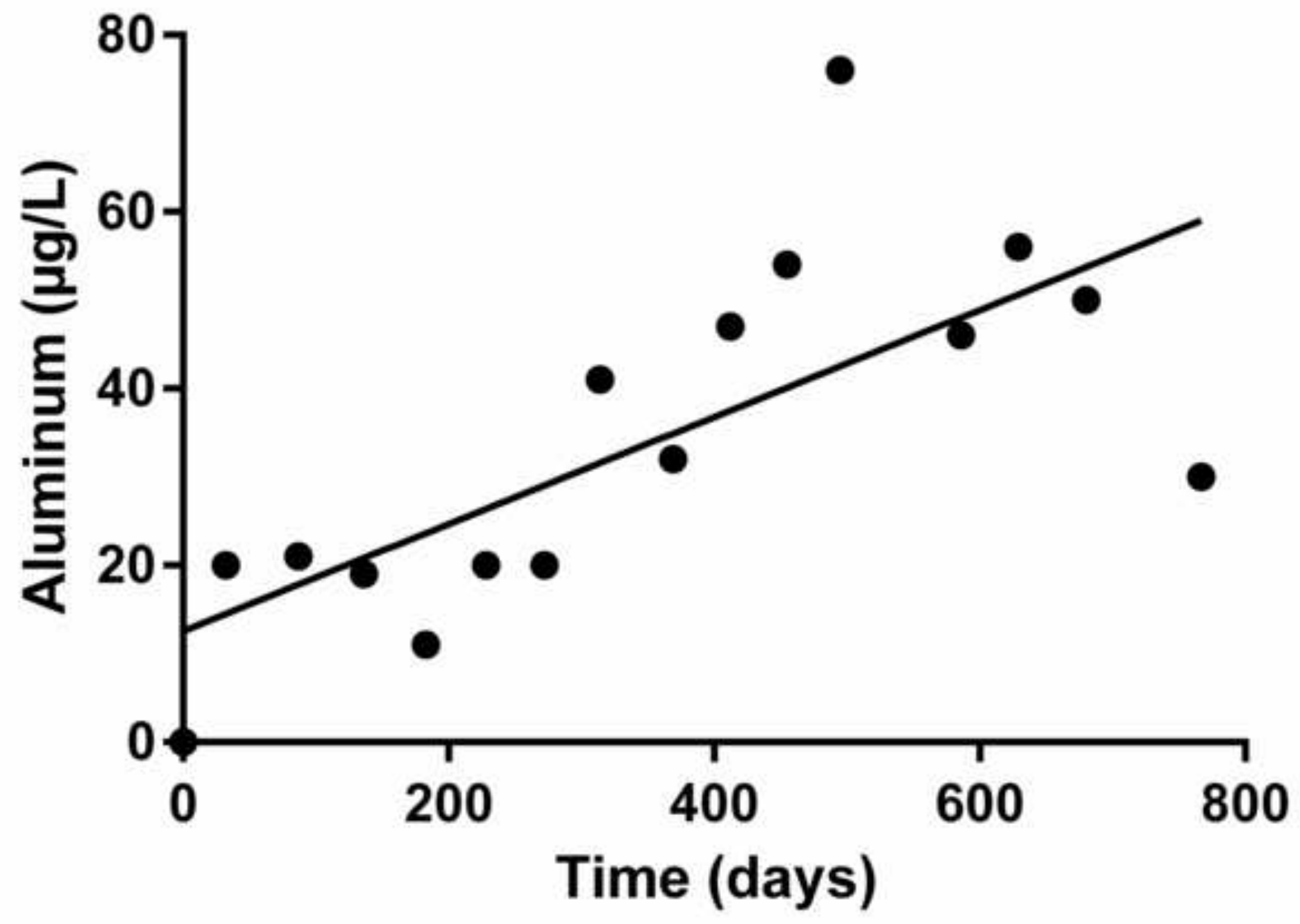


Table 1. Reported aluminum concentrations in calcium gluconate.

\begin{tabular}{|c|c|c|}
\hline Source (as stated in the reference) & $\begin{array}{l}\text { Aluminum } \\
\text { concentration } \\
(\mu \mathrm{g} / \mathrm{L})\end{array}$ & Reference \\
\hline \multicolumn{3}{|l|}{ Packaged in glass } \\
\hline Calcium gluconate $10 \%$ & 5056 & (2) \\
\hline Calcium, Sandoz & 3753 & (28) \\
\hline Calcium gluconate, Lymphomed & $\begin{array}{l}2245 \text { (range } 2000 \text { to } \\
2586 \text { ) }\end{array}$ & \multirow{5}{*}{ (13) } \\
\hline Calcium gluconate, Invenex & $2592 \& 2610$ & \\
\hline Calcium gluconate, Elkins Sinn & $\begin{array}{l}3973 \text { (range } 1095 \text { to } \\
5565 \text { ) }\end{array}$ & \\
\hline Calcium gluconate, IMS & 3299 & \\
\hline Calcium gluconate, American quinine & 2286 & \\
\hline $10 \%$ Calcium gluconate, Phoenix & 3430 & (29) \\
\hline Calcium gluconate & 4850 & (30) \\
\hline Ca gluconate, Lymphomed & $\begin{array}{l}2375 \text { (range } 2000 \text { to } \\
2750 \text { ) }\end{array}$ & (31) \\
\hline Calcium gluconate & 1100 to 5600 & (14) \\
\hline Calcium gluconate $10 \%$, Pharmacie Centrale AP Paris & $675 \& 1830$ & \multirow{2}{*}{ (32) } \\
\hline Calcium gluconate $10 \%$, Arguettant & 1890 & \\
\hline Calcium gluconicum, Braun & 3825 & (3) \\
\hline Calcium gluconate, Palex & 5437 & (33) \\
\hline Calcium gluconate $0.22 \mathrm{mmol} / \mathrm{mL}$, David Bull Labs. Pty. Ltd. & 5800 & \multirow{3}{*}{ (34) } \\
\hline Calcium $10 \%$, Sandoz & 4900 & \\
\hline Calcium gluceptate $10 \%$ & 4800 & \\
\hline
\end{tabular}


Table 1. Reported values of the aluminum concentration in calcium gluconate. (cont.)

\begin{tabular}{|c|c|c|}
\hline Calcium $10 \%$, Braun & $4734 \& 6243$ & \\
\hline Calcium $20 \%$, Braun & 10,695 & (35) \\
\hline Calcium-gluconat $10 \%$, Pharma Hameln & 4421 & \\
\hline Calcium gluconate $10 \%$, Meram & 5940 & \multirow{3}{*}{ (15) } \\
\hline Calcium gluconate $10 \%$, Aguettant & 5940 & \\
\hline Calcium gluconate, AP Paris & 6130 & \\
\hline Calcium gluconate, American Regent & $4201 \pm 267$ & $(16)$ \\
\hline $10 \%$ Calcium gluconate, Commercial Polfa & 4400 & $(36)$ \\
\hline Calcium gluconate $10 \%$ (10 ml vial) & 5000 & \multirow{3}{*}{ (37) } \\
\hline Calcium gluconate $10 \%$ (100 ml vial) & 3000 & \\
\hline Calcium gluconate $20 \%$ (10 ml vial) & 6000 & \\
\hline Halex Istar (lot 1) & 5621 & \multirow{5}{*}{$(22)$} \\
\hline Halex Istar (lot 2) & 6781 & \\
\hline Ariston & 5960 & \\
\hline B. Braun & 4530 & \\
\hline Elkins Sinn & 3987 & \\
\hline Calcium gluconate $10 \%$ & $5621 \& 5960$ & $(25)$ \\
\hline Calcium gluconate $5 \%, \mathrm{PCH}$, Paris, France & 680 & (17) \\
\hline Calcium gluconate $10 \%$ & $\begin{array}{l}2712 \text { (range } 2240 \text { to } \\
3040 \text { ) }\end{array}$ & (38) \\
\hline Calcium gluconate $10 \%$, Hypofarma & $9205 \& 19,400$ & $(18)$ \\
\hline Calcium gluconate & 3234 & (39) \\
\hline Calcium gluconate $10 \%$ (new) & 4910 & \multirow{2}{*}{$(40)$} \\
\hline Calcium gluconate $10 \%$ (old) & 6150 & \\
\hline
\end{tabular}


Table 1. Reported values of the aluminum concentration in calcium gluconate. (cont.)

\begin{tabular}{|c|c|c|}
\hline Calcium gluconate 100 mg/ml, American Pharmaceutical Partners & $\begin{array}{l}2812 \text { (range } 1969 \text { to } \\
3495 \text { ) }\end{array}$ & \multirow{2}{*}{ (41) } \\
\hline Calcium gluconate $100 \mathrm{mg} / \mathrm{ml}$, American Regent & $\begin{array}{l}2487 \text { (range } 1928 \text { to } \\
2887 \text { ) }\end{array}$ & \\
\hline Calcium gluconate $10 \%$ & range: 4000 to 4400 & (42) \\
\hline Calcium gluconate $10 \%$, PISA Farmaceutica & 3890 & $(20)$ \\
\hline Calcium gluconate $20 \%$ & $\begin{array}{l}4000 \text { (range } 3100 \text { to } \\
4200 \text { ) }\end{array}$ & (21) \\
\hline \multicolumn{3}{|l|}{ Packaged in plastic } \\
\hline $\begin{array}{l}\text { Calcium gluconate } 10 \% \text {, Braun } \\
\text { Calcium gluconate } 20 \% \text {, Braun }\end{array}$ & $\begin{array}{l}105 \\
195\end{array}$ & (37) \\
\hline Calcium gluconate $10 \%$ & $\begin{array}{l}27 \& 30 \text { (new) } \\
31 \& 33 \text { (old) }\end{array}$ & $(40)$ \\
\hline
\end{tabular}


Table 2. Reported aluminum concentrations $(\mu \mathrm{g} / \mathrm{L})$ in phosphates, heparin and albumin.

\begin{tabular}{|c|c|c|c|c|}
\hline \multicolumn{2}{|l|}{ Phosphate } & \multirow{3}{*}{$\begin{array}{c}\text { Heparin } \\
1000 \mathrm{U} / \mathrm{mL} 684 \\
5000 \mathrm{U} / \mathrm{mL} 359 \\
10,000 \mathrm{U} / \mathrm{mL} 468\end{array}$} & \multirow{3}{*}{$\begin{array}{l}\text { Albumin } \\
25 \% 1822\end{array}$} & \multirow{3}{*}{$\begin{array}{c}\text { Reference } \\
\text { (2) }\end{array}$} \\
\hline Potassium phosphate $3 \mathrm{M}$ & 16,598 & & & \\
\hline Sodium phosphate $3 \mathrm{M}$ & 5056 & & & \\
\hline Potassium phosphate $1 \mathrm{M}$ & 486 & & 1296 & (28) \\
\hline Potassium phosphate & $\begin{array}{c}92 \& 2189 \\
\text { (2069 to 2301) }\end{array}$ & & $\begin{array}{c}25 \% 914 \& \\
2364(1116 \text { to }\end{array}$ & \\
\hline Sodium phosphate & $\begin{array}{c}6 \& 2236(2026 \\
\text { to } 2370)\end{array}$ & & 5849) & (13) \\
\hline Potassium acid phosphate & 1882 & & & (29) \\
\hline $\begin{array}{l}\text { Potassium acid phosphate } 13.6 \% \\
\qquad(1 \mathrm{M})\end{array}$ & 2154 & & & (30) \\
\hline Potassium phosphate & $\begin{array}{c}2754(2025 \text { to } \\
7128)\end{array}$ & & & (31) \\
\hline Sodium phosphate & $65\left(\mathrm{ND}^{*}\right.$ to 284$)$ & & & \\
\hline Potassium phosphate & 90 to 2300 & & & \\
\hline Sodium phosphate & $<5$ to 2370 & & & (14) \\
\hline & & & $\begin{array}{l}5 \% 164 \\
20 \% 28\end{array}$ & (3) \\
\hline Potassium phosphate & 9539 & & & \\
\hline Monopotassium phosphate $1 \mathrm{M}$ & 1533 & & & (33) \\
\hline Dipotassium phosphate $1 \mathrm{M}$ & 3615 & & & \\
\hline Monosodium phosphate $1 \mathrm{M}$ & 1451 & & & \\
\hline
\end{tabular}


Table 2. Reported aluminum concentrations $(\mu \mathrm{g} / \mathrm{L})$ in phosphates, heparin and albumin. (cont.)

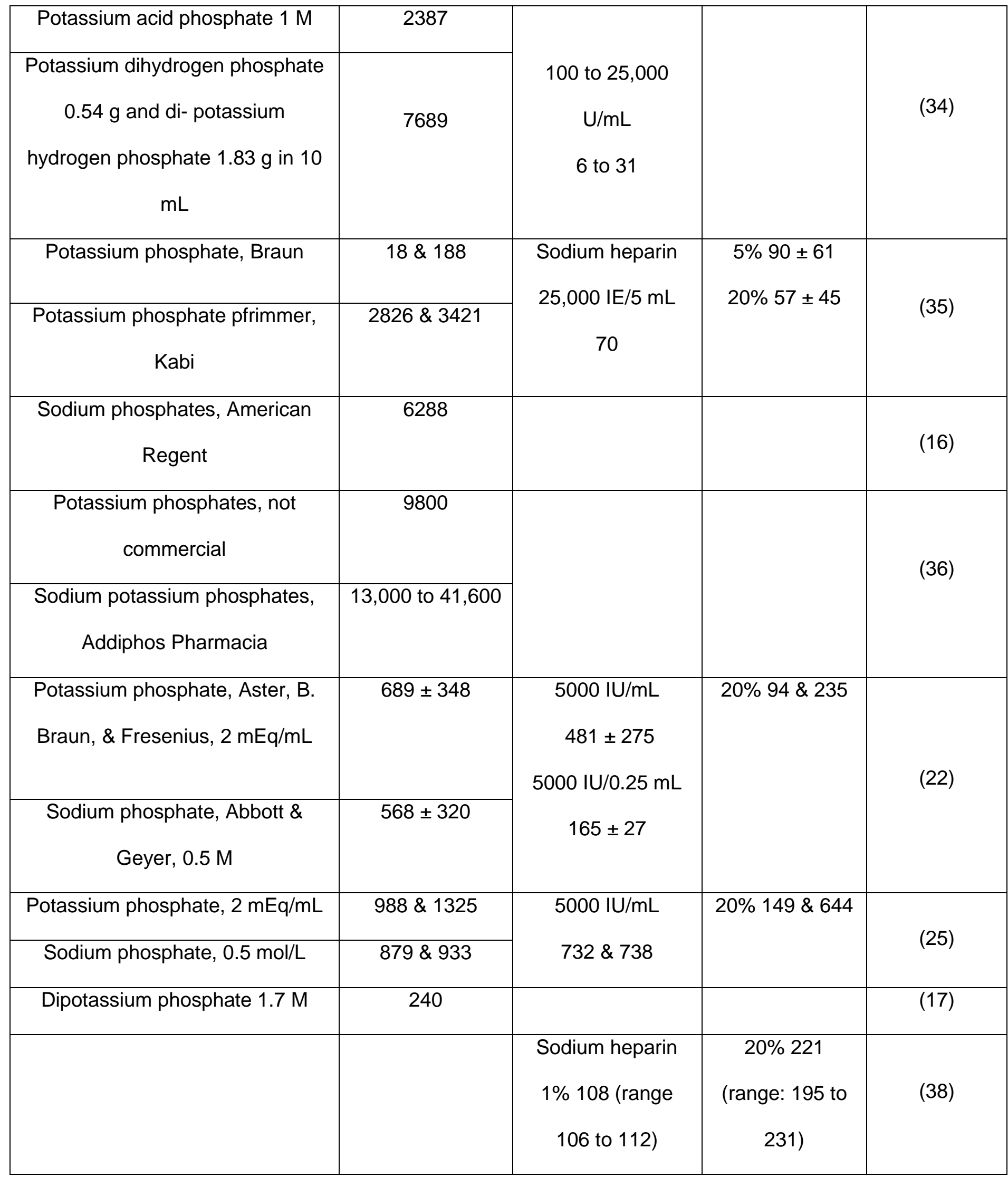


Table 2. Reported aluminum concentrations $(\mu \mathrm{g} / \mathrm{L})$ in phosphates, heparin and albumin. (cont.)

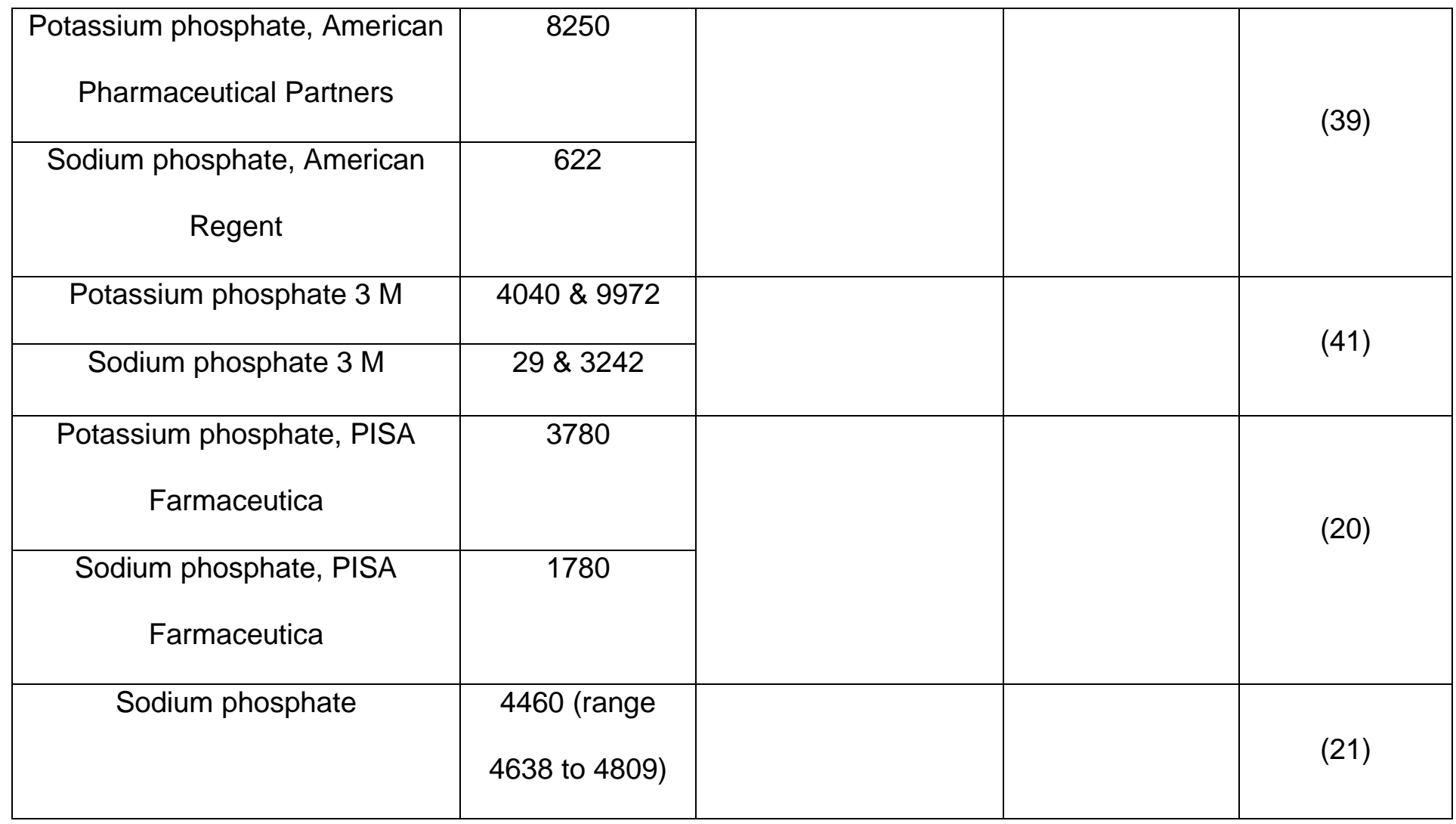

${ }^{*}=$ not detected 


\section{Supplemental Information to: Aluminum and phthalates in calcium gluconate; contribution from glass and plastic packaging}

\section{Materials and Methods:}

Materials:

Twenty-five $10 \mathrm{ml}$ glass vials of Calcium Gluconate Injection, USP (APP Pharmaceuticals, LLC, Schaumburg, IL; Product Code 31110, NDC No. 63323-311-10, Lot 6005911 , Expiration April, 2015), ten $10 \mathrm{ml}$ glass ampoules of Gluconate de Calcium Lavoisier 10\% (C.D.M. Lavoisier, 75017 Paris, France; Lot 2A154, Expiration September, 2015), and twenty $10 \mathrm{ml}$ plastic ampulles of Calciumgluconat $10 \%$ B. Braun Injektionslösung (B. Braun Melsungen AG - 34209 Melsungen, Deutschland; Lot 12417011; Expiration September, 2015) were obtained in July, 2013. One 10 plastic vial of Calcium Gluconate Injection, USP (Fresenius Kabi, LLC, Lake Zurich, IL; Product Code 31110, NDC No. 63323-311-19, Lot 6009399, Expiration March, 2016), was obtained in May, 2015. EPA Method 506 Phthalates Mixture containing bis(2-ethylhexyl) adipate, bis(2-ethylhexyl) phthalate (DEHP), butyl benzyl phthalate, di-n-butyl phthalate, dimethyl phthalate, diethyl phthalate, and di-n-octyl phthalate (Ultra Scientific); an internal standard mix containing acenaphtene-d10, chrysene-d12, 1,4-dichlorobenzened4, naphthalene-d8, perylene-d12, and phenanthrene-d10 (Restek); and an EPA Method 3500 (SW-846) and CLP-Semi-Volatiles Base/Neutrals Surrogates mixture containing 2-fluorobiphenyl, nitrobenzene-d5, and p-terphenyl-d14 (Restek) were obtained from VWR. 
Methods:

Sample collection:

Approximately half of the $10 \mathrm{ml}$ calcium gluconate contents of individual containers from APP Pharmaceuticals and B. Braun was clean poured into duplicate seven $\mathrm{ml}$ perfluoroalkoxy alkanes (PFA) vials (Savillex, Eden Prairie, MN) at $\sim 1.5$ month intervals. Approximately half of the $10 \mathrm{ml}$ contents of ampoules from C.D.M. Lavoisier was clean poured into duplicate seven ml PFA vials at $\sim 1.5$ month intervals initially, then at three month intervals. Approximately half of the $10 \mathrm{ml}$ contents of the Fresenius Kabi product was clean poured into duplicate seven ml PFA vials September 8, 2015. Sample transfer was conducted in a Class 100 laminar flow hood. The PFA vials had been pre-cleaned by soaking in $10 \%$ nitric acid then $5 \mathrm{~mm}$ EDTA, and triple rinsed with 18.2 M $\Omega-\mathrm{cm}$ water. Water $(18.2 \mathrm{M} \Omega-\mathrm{cm})$ from a Barnstead NANOpure water polishing system, stored in a $500 \mathrm{ml}$ FEP bottle that had been triple cleaned with trace metal grade nitric acid, was clean-poured into duplicate PFA vials on many of the same occasions calcium gluconate samples were transferred, to serve as a blank. All samples before and after transfer to PFA vials were stored at room temperature throughout the study.

Aluminum quantification in calcium gluconate solutions by ICP-MS:

Immediately prior to analysis, samples were heated to solubilize precipitation and then diluted two-hundred-fold with $1 \%(\mathrm{v} / \mathrm{v})$ concentrated ultra-pure nitric acid. Results were compared to a standard curve created from an Inorganic Ventures (Christiansburg, VA, USA) multi-element ICP-MS standard. To validate the calibration curve, a standard of 
known concentration was prepared from a multi-element standard of a different lot number and analyzed as an unknown. Two samples were diluted and analyzed a second time as sample dilution replicates. Spike recovery was determined by adding 10 $\mu \mathrm{L}$ of the $10 \mathrm{mg} / \mathrm{L}$ calibration standard to two $10 \mathrm{~mL}$ samples, adding $10 \mu \mathrm{g} / \mathrm{L}$ aluminum. Scandium was added as the internal standard to all samples and standards for the aluminum analyses at the same concentration (approximately five $\mu \mathrm{g} / \mathrm{L}$ ). The instrument detection limit was calculated as three times the standard deviation of the eleven reagent blanks. Care was taken to minimize metal contamination, including use of metal-free centrifuge tubes, trace metal grade nitric acid, and $18.2 \mathrm{M} \Omega-\mathrm{cm}$ water. All dilution procedures were conducted in a class 100 laminar flow hood. Samples were analyzed by ICP-MS (Agilent 7500cx, Santa Clara, CA, US).

Aluminum analysis of glass vials by laser ablation ICP-MS:

A glass vial that contained Calcium Gluconate Injection, USP from APP

Pharmaceuticals and a glass ampoule that contained Gluconate de Calcium from Lavoisier were wrapped in paper and shattered using a hammer. Samples from the bottom of each vial were collected and rinsed thoroughly with deionized water. The samples were them mounted on microscope slides using double sided tape with the inside surface of the bottom of the vials facing up. The samples were analyzed using a $213 \mathrm{~nm}$ laser ablation system (CETAC Technologies LSX-213, Omaha, NE, USA) coupled to an inductively coupled plasma mass spectrometer (Agilent Technologies 7500CX, Santa Clara, CA, USA). Duplicate samples from each vial were ablated with 100 laser shots at a frequency of $20 \mathrm{~Hz}$ within a $200 \mu \mathrm{m}$ spot. Standardization was 
performed by ablating standards with known aluminum concentrations in a calcium carbonate matrix in the same manner. These standards were prepared by mixing a known mass of aluminum contained within an ICP-MS standard solution (Inorganic Ventures, Christiansburg, VA, USA) with a known mass of calcium carbonate, drying the mixture, and pressing it into pellets with a pellet press. We were not able to make or obtain standards with a glass matrix that had known aluminum concentrations. Consequently, although the numbers are precise, they may not be accurate because laser ablation is highly matrix dependent. The true aluminum concentration may be different by as much as 10 -fold. The aluminum concentration in the glass of the glass vial from APP was $2082 \pm 170(\mathrm{SD}) \mathrm{mg} / \mathrm{kg}(\sim 0.2 \%)$ and in the glass of the glass ampoule from Lavoisier: $2224 \pm 228(\mathrm{SD}) \mathrm{mg} / \mathrm{kg}(\sim 0.2 \%)$. These results indicate there was no significant difference in the aluminum concentration between these two containers, but must not be cited as accurate determinations of aluminum concentration. Reports of the aluminum concentration in glass vials include $5.8 \% \mathrm{Al}_{2} \mathrm{O}_{3}$ (or 3.1\% Al) in Type I USP borosilicate hard glass and $1.9 \% \mathrm{Al}_{2} \mathrm{O}_{3}$ (or $1 \% \mathrm{Al}$ ) in Type II USP soft glass (1), 0.61 to $3.01 \%$ aluminum (2), and $5 \% \mathrm{Al}_{2} \mathrm{O}_{3}$ (or $2.6 \% \mathrm{Al}$ ) in Type I USP glass (3).

Phthalate analysis in calcium gluconate solutions by gas chromatography - mass spectrometry:

A method was developed based on a modification of EPA method 8270D that separated the seven components of the phthalates mixture, with retention times from 12.95 to 25.12 minutes. DEHP eluted at 23.65 minutes. The method also separated the 
phthalates from the six internal standard components, which had retention times from 6.74 to 26.49 minutes, and the three surrogates, which had retention times from 7.85 to 20.92 minutes. A calibration curve was prepared containing $0.1,1.0,2.5,5.0,7.5$, and 10 ppm phthalates. Five blanks were prepared (water, water exposed to pipette tip from the lot used to prepare the dilutions of calcium gluconate for ICP-MS aluminum quantification [above], Calcium Gluconate Injection USP, Calcium Gluconate Injection USP in PFA vial, and Calcium Gluconate Injection USP exposed to pipette tip). Phthalate recovery was determined from water and Calcium Gluconate Injection USP in PFA vials, by addition of $5 \mathrm{ppm}$ phthalates. Samples of $10 \%$ calcium gluconate from APP Pharmaceuticals, Lavoisier, and B. Braun from the last collection date (August 25, 2015) and the Fresenius Kabi sample were analyzed for their phthalate content. Five $\mu \mathrm{L}$ of $1000 \mathrm{ppm}$ surrogate mix was added to the blanks, spiked samples, and $10 \%$ calcium gluconate samples (four to five $\mathrm{ml}$ ) which were then extracted by adding three $\mathrm{ml}$ dichloromethane, shaken vigorously for five minutes, then transferring the organic layer to a separate vial. The extraction step was repeated and the extracts were combined and evaporated under a gentle stream of nitrogen to near dryness, the vial was rinsed and brought to a final volume of one $\mathrm{ml}$ with dichloromethane. Two $\mu \mathrm{L}$ of $2000 \mathrm{ppm}$ internal standard mix was added to each of the extracts and calibration curve components. The samples were analyzed on a Varian CP-3800 GC with a Varian Saturn 2200 MS.

Phthalate analysis in leachates from plastic containers by gas chromatography - mass spectrometry: 
The B. Braun plastic container that provided the last measured sample, on August 25, 2015, and the Fresenius Kabi plastic container were used to determine if phthalates would leach from the plastic. A portion of the bottom of each container was removed and weighed (B. Braun $0.311 \mathrm{~g}$; Fresenius Kabi $0.371 \mathrm{~g}$ ) and placed in $24 \mathrm{ml}$ vials with five $\mathrm{ml}$ of dichloromethane. The vials were agitated by sonication and vortex mixing for 10 minutes. One $\mathrm{ml}$ of the extract was transferred to an autosampler vial adding two $\mu \mathrm{L}$ of internal standard mix. Samples were analyzed by GC-MS as described above for the detection of phthalates.

1 Inoue $\mathrm{M}$, Gion $\mathrm{Y}$, Itoh $\mathrm{H}$, et al. Reduction of aluminium concentration in albumin products. Vox Sanguinis 1994;66(4):249-52.

2 Bohrer D, do Nascimento PC, Binotto R, et al. Influence of the glass packing on the contamination of pharmaceutical products by aluminium. Part I: salts, glucose, heparin and albumin. J Trace Elem Med Biol 2001;15(2-3):95-101.

3 Biavati A, Amadei P, Ferrarini A, et al. Significance of aluminium release from type I borosilicate glass containers. Pharmazeutische Industrie 2010;72(12):2144-47. 